\title{
Waste processing method and environmental protection in the agro-industrial complex
}

\author{
Valeria Kireeva ${ }^{1, *}$ \\ ${ }^{1}$ Don State Technical University, Gagarina sq., 1, 344003 Rostov-on-Don, Russia
}

\begin{abstract}
The article presents the features of conservation of leafy mass of high-protein crops of the legume family, the disadvantages of traditional preparation of biomass for silage in fodder production. The results of studying the possibility of reducing plant moisture by mechanical means, using the press residue as a raw material for making haylage, and brown juice as a preservative are presented. The results of the development of a method for silage of the pressed alfalfa residue with the introduction of fermented brown juice enriched with the metabolic products of lactic acid and propionic acid bacteria - organic acids, to intensify the process of fermentation of feed. The analysis of the chemical composition of plant raw materials and the obtained haylage was carried out, the value of fodder, energy value and potential harmlessness for feeding to animals was determined.
\end{abstract}

\section{Introduction}

An important reserve of raw materials for the production of fodder protein is organic waste of agricultural field cultivation [1]. Their insufficient use as raw materials for obtaining animal feed leads to an unjustified overconsumption of grain used for forage purposes.

At present, the task of developing methods and technological methods for the disposal of wastes from the processing of agricultural plants to obtain fodder products with high palatability, digestibility and nutritional value is urgent.

Field crop waste has many disadvantages - it requires additional processing, has high humidity, insufficient nutritional value, or contains unwanted components.

These disadvantages can be avoided by receiving fodder from the waste of processing of green leaf-stem mass of ordinary and perennial seeded forage legumes.

The traditional fodder production of haylage for feeding animals in winter is a method of preserving plant mass, which is pre-dried to a moisture content of $40-55 \%$ and then stored under anaerobic (without oxygen) conditions.

The $\mathrm{pH}$ value of haylage, required for fermentation of feed, and during ensiling, decreases due to the vital activity of lactic acid fermentation, but is higher than that of silage - 4.4-5.0.

The preservation of haylage for a long time is ensured not only due to the low acidity, but also due to the lower humidity and physiological dryness of the original plant raw materials, preserved under anaerobic conditions, as well as biochemical processes caused by the

\footnotetext{
*Correcting author valeriakireeva@gmail.com
} 
microorganisms present in it.

For harvesting raw materials for making haylage, it is preferable to use herbaceous crops of the legume family - alfalfa, clover, since they are difficult to feed and are not very suitable for harvesting hay.

The advantages of forage from legumes in comparison with cereals include the enrichment of the balance in amino acid composition with protein, the content of which in winter rations of farm animals continues to be in short supply.

In contrast to the processes occurring during ensiling, conservation of dried plant mass by silage occurs mainly due to the low degree of availability for the metabolism of water contained in the biomass of bacteria and nutrients dissolved in it, due to an increase in osmotic pressure in cells that occurs during evaporation and dehydration. When silaging the mass, dried to a dry matter content of 45-55\%, most of the undesirable accompanying microflora (putrefactive, butyric, enterobacteria) exhibits low activity and develops poorly.

The useful microflora contained in the biomass laid in silage is the same as in silage, but the number of bacteria is less, therefore microbiological processes during silage are much slower than during silage [2].

When silage is a protein-rich dried plant mass in the first days of fermentation, putrefactive bacteria actively multiply, and the number of lactic acid bacteria cells increases only seven days after the feed was placed for storage. Therefore, the existing methods of ensiling hard-to-feed plants usually provide for the introduction of bacterial starter cultures into the green mass [3]. The chemical and microbiological composition of the finished haylage largely depends on the degree of maturity and the method of harvesting green mass, the type of canning and storage conditions [4].

Plants for making haylage for feeding, for example, for horses are often mowed in the late stages of the growing season, which is possibly associated with an increased risk of compromising the hygienic quality of forage and short-term aerobic storage stability after opening the storage, but information in this area is scarce.

The prepared good-quality haylage contains 2.4 times less lactic acid than silage, butyric acid is absent in it, the $\mathrm{pH}$ of haylage is also lower than in silage and is 4.7-5.

Plants during the growing season normally contain epiphytic microorganisms on their aboveground part, which are natural inhabitants of plant surfaces or are brought in with dust and insects. Bacteria, actinomycetes, fungi, and yeasts inhabit all surfaces of healthy plants.

These microorganisms are not parasites, but symbionts, they use normal secretions formed as a result of metabolic processes of plant cells, as well as organic pollution, which protects plants from disease-causing microorganisms.

Some of the normally present epiphytes are potentially pathogenic and acquire parasitic properties when plant immunity is weakened. When cellular structures are destroyed, plants lose their protective functions.

Having reached a critical concentration, phytopathogenic microorganisms cause diseases - gum, resin, mucus, dry and wet rot, powdery mildew, rot and, when processing green mass, get into the feed obtained from it and then into the animal's body [5].

During harvesting, the plant mass is also exposed to contamination with dust and soil containing microbes [6]. The accumulation of unwanted microorganisms, and therefore feed spoilage, depends on the moisture content of the biomass and the ambient temperature. In the plant mass dried up to $45 \%$ of dry matter, the development of harmful microorganisms that form mold and rot is suppressed.

To prepare haylage, in addition to timely harvesting, to reduce the moisture content of raw materials, it is necessary to provide the required degree of natural traditionally used field wilting of plants (up to $45-50 \%$ dry matter), which inevitably leads to high losses of the most valuable part - small leaves [7].

It is possible to reduce the moisture content of the plant mass by pressing, in which it is 
separated into a press residue and green juice. In fodder production, protein concentrates can be obtained from alfalfa green juice for introduction into winter diets of monogastric animals.

The resulting by-products - brown juice and pressed residue, are considered as waste, practically not used and taken to unorganized landfills, littering and swamping the environment.

In the process of 3 -fold pressing, the moisture content of the biomass is reduced to $62.2 \%$. From the green mass of alfalfa with a moisture content of $76-82 \%$, the yield of the pressed residue is $45-60 \%$.

The chemical composition of the pressed residue changes depending on the cut and the mode of processing of the original green mass. In the first mowing in the budding-beginning of flowering phase, the biomass of the pressed pulp contains up to $70 \%$ of nutrients transferred from the green mass, which creates favorable conditions for canning and obtaining good-quality animal feed.

It is also known that in the cells of dehydrated plants, the amylase enzyme is activated, which hydrolyzes starch molecules, resulting in the accumulation of water-soluble easily digestible carbohydrates (sugars) in the feed. As a result, the concentration of water-soluble carbohydrates increases, which creates favorable conditions for the development of lactic acid bacteria during the silage of even high-protein, difficult-to-feed crops [8].

Brown juice also contains some of the nutrients left over after protein separation and can be used for addition to dry feed or for preparation of fertilizers [9].

In this regard, it seemed relevant to study the possibility of preparing a good-quality feed from a press residue - a waste of processing the vegetative mass of plants, which makes it possible to increase the efficiency of using agricultural plants.

\section{The purpose of study}

Consisted in the development of a resource-saving method for the disposal of waste from the processing of the vegetative mass of alfalfa, based on silage of the pressed residue with fermented brown juice added in the form of a preservative, contributing to the expansion of crop production, disposal of its waste and environmental protection.

\section{Methods}

As a result of squeezing the cell juice from the green mass of alfalfa, a by-product is formed - a pressed residue with a characteristic herbal odor, in which particles of 15-20 mm make up to $80 \%$, particles of $30-50 \mathrm{~mm}$ make up $20 \%$.

Fermentation of brown juice was carried out by growing strains of lactic acid microorganisms of the genus Lactobacillus and propionic acid of the genus Propionibacterium for introduction into biomass in order to intensify the silage process.

In the experiments, separate and joint cultivation of lactic acid and propionic acid bacteria on brown alfalfa juice was used.

Before the bacteria were inoculated, the brown juice was sterilized by autoclaving to remove the accompanying unwanted microflora. Previously, it was neutralized to $\mathrm{pH} 6.5$ by introducing a $20 \%$ sodium hydroxide solution.

The degree of reproduction and development of lactic acid and propionic acid bacteria was assessed by the change in the number of bacterial cells in $1 \mathrm{ml}$ of juice suspension.

In the suspension, the $\mathrm{pH}$ level, the content of water-soluble carbohydrates, and the accumulation rate of synthesized organic acids were determined by conventional methods.

The press residue, mixed with fermented brown juice, was placed in containers and sealed with lids. Aerobic feed stability is a key factor in high nutrient retention with minimal 
contamination of mold spores and toxins [10].

The containers were moved to a room with a constant maintained temperature of $+15^{\circ}$ $\mathrm{C}$ for storage, the period of which was 6 months.

As a control, a press residue was put into storage without adding a bacterial starter culture.

After the expiration of the shelf life, the feed was unloaded from the containers and the feed value and energy nutritional value of the obtained haylage were determined by conventional methods.

The quality of the obtained products of alfalfa leafy mass was considered in comparison with the fodder obtained from the traditionally used raw materials in fodder production, in accordance with the regulations for traditionally produced haylage.

In the experiments, the chemical composition of the initial plant raw material and the resulting haylage, the value of gross and exchange energy were determined, the quality of feed during storage was studied using conventional methods.

The quality of the obtained products of fractionation of the alfalfa leafy mass was considered in comparison with the fodders obtained from the traditionally used raw materials in fodder production.

Determination of moisture content, mass fraction of total nitrogen and protein, fiber, fat was carried out by methods using spectroscopy in the near infrared region, ash elements by dry ashing, carotene - by photometric determination of the optical density of a solution.

The determination of the mass fraction of organic acids was carried out by capillary electrophoresis.

\section{Results}

The program of this research included the processing of the green mass of blue hybrid alfalfa 1 cut, mown in the budding-beginning of flowering phase, when the accumulation of nutrients in the leafy mass is maximum [9]. During processing, the green mass was squeezed out on a press installation, as a result of which it was separated into a solid fraction - the pressed residue and a liquid - green cell juice.

Upon further fractionation of green juice using acidic precipitation of proteins, it was also divided into two fractions - solid protein and liquid - brown juice. After separation of the protein fraction, which is used to prepare the feed additive - protein green concentrate (PGC), brown juice remains, which is usually considered as a production waste and is discharged together with the wash water.

The pressed residue also refers to production waste; attempts to dry it to obtain grass meal are not widely used due to the high energy intensity of the process and the loss of nutrients when exposed to high temperatures.

The alfalfa press residue obtained during pressing had a significant fodder value and moisture content, at which it is advisable to use it as a raw material for silage and to obtain additional animal feed.

The brown juice also contained residual amounts of nutrients, allowing it to be used as an agent for intensifying the silage process, due to the presence of soluble carbohydrates sugars.

During silage, the preservation of feed nutrients is ensured due to the physiological dryness of the fermented raw materials and the filling of microcavities with carbon dioxide. But microbiological processes of sugar fermentation by bacterial microflora, although less intense than in silage, are still going on.

The use of microbiological starter cultures promotes efficient fermentation of difficult to ensilage high-protein grasses with a low content of soluble carbohydrates, such as alfalfa.

The content in brown juice of a certain amount of soluble carbohydrates monosaccharides made it possible to use it as a medium for the cultivation of microorganisms 
and enrichment with organic acids and microbial protein

The experiments assumed the use of alfalfa press residue for the preparation of haylage, into which brown juice enriched with products of bacterial metabolism is introduced to intensify the haylage process.

Fermentation of brown juice was carried out by the introduction of strains of microorganisms of lactic acid and propionic acid bacteria.

A lactic acid bacteria starter was added to the brown juice of alfalfa to sour the brown juice and prevent the development of unwanted microflora.

This strain is highly active and provides hydrolysis of high molecular weight complex polysaccharides contained in brown juice to simple monomers - monosaccharide.

Strains of lactic acid bacteria of the genus Lactobacillus were selected on the basis that they are a natural inhabitant of the intestinal microflora of animals and are a proven inoculant widely used in traditional ensiling $[11,12]$. They have the ability to improve the aerobic stability of the feed without adversely affecting the productivity of animals [13].

Although there are a large number of studies evaluating the importance of lactobacilli in silage preparation, the potential use of these microorganisms in combination with fermentable biomass is not fully understood [14].

Lactic acid bacteria were also introduced to stimulate the synthesis of organic acids necessary for the development of propionic acid bacteria. The cells of lactic acid bacteria have an increased osmotic pressure, which allows them to actively multiply and show vital activity when the development of putrefactive microorganisms is suppressed.

Lactic acid bacteria in the process of their metabolism ferment monosaccharides mannose, rhamnose, sorbitol, as well as dextrin and starch, forming lactic and acetic acids, which are the main products of fermentation. Microbiological processes occur intensively in the first 7-15 days of fermentation of the mass.

Propionic acid bacteria are of interest for feed preparation due to the fact that they are natural symbionts of the rumen of ruminants, capable of synthesizing vitamin B12, and their biomass has nutritional value for animals.

During the study, the strains of the genus Propionibacterium were selected on the basis of the fact that they are capable of producing a number of beneficial compounds for animals - nutraceuticals, while showing low growth requirements. In the course of their metabolism, propionic acid bacteria synthesize organic sppionic and acetic acids necessary to intensify the silage process.

The use of viable propionic acid bacteria for fermentation of brown juice was also determined by their resistance to antibiotics. The use of broad-spectrum antibiotics and some other drugs in animal husbandry has a suppressive effect not only on pathogenic, but also vital natural intestinal symbionts, which leads to a disturbance in the animal's body of its own microflora, and, as a consequence, to the development of dysbiosis.

Propionic acid bacteria also have antagonistic activity against pathogenic bacteria belonging to the genus Shigella, which are the causative agents of dysentery and Salmonella, the causative agents of salmonellosis.

Propionic acid bacteria are able to actively develop in the biomass of various plants, including corn, sugar beet tops, and alfalfa.

In the experiments, lactic acid and propionic acid bacteria were cultivated on brown alfalfa juice obtained in the field of separation of protein fractions.

Due to the peculiarities of their metabolism, propionic acid bacteria are able to activate the process of fermentation and silage while preventing peroxidation of the fermented mass.

To prepare the bacterial starter, propionic acid bacteria were grown in a medium made from blood-whey broth together with acidophilic bacteria, which stimulate the synthesis of vitamin B12 and organic acids, propionic acid bacteria.

During the experiments, the dynamics of the development of propionic acid and lactic 
acid bacteria in the periodic system of cultivation on brown alfalfa juice in monocultures and in combination was studied.

Before the bacteria were inoculated, the brown juice was sterilized by autoclaving to remove the accompanying unwanted microflora. Previously, it was neutralized to $\mathrm{pH} 6.5$ by introducing a $20 \%$ sodium hydroxide solution. The degree of reproduction and development of bacteria was assessed by the change in the number of bacterial cells in $1 \mathrm{ml}$ of juice suspension.

The suspension was determined by the $\mathrm{pH}$ level, the content of soluble carbohydrates, the intensity of the accumulation of synthesized organic acids by conventional methods.

It was found that in the process of anaerobic fermentation and accumulation of bacterial biomass in brown juice, the $\mathrm{pH}$ and the content of water-soluble carbohydrates consumed for metabolic processes of microflora decreased.

The dynamics of changes in the $\mathrm{pH}$ level and sugar content in brown juice showed that the most intense decrease in acidity was observed during the fermentation of brown juice by lactic acid bacteria and was 4.5 on the third day.

When propionic acid bacteria were grown on brown juice, the $\mathrm{pH}$ dropped to 4.8 , and when these strains were fermented together, to 4.7 .

The accumulation of biomass during separate and joint cultivation also had differences.

During fermentation of brown juice with lactic acid bacteria, the greatest accumulation of biomass occurred on days 2-3, after which there was a decrease in the number of cells as a result of their natural death.

In propionic acid strains, the greatest accumulation of microbial biomass was observed on 3-4 days, followed by a decrease and withering away after 7-8 days of fermentation.

The maximum number of microbial cells differed insignificantly and amounted to: lactobacilli $6 \cdot 109 \mathrm{ml} / \mathrm{ml}$, propionic acid $-5 \cdot 109 \mathrm{ml} / \mathrm{ml}$.

During joint fermentation, the death of lactic acid bacteria occurred much later - 5-7 days after the start of fermentation, which was probably caused by the stimulating effect of propionic acid bacteria on their development.

In the fermented medium, the sugar content decreased as a result of the consumption of the bacterial mass.

The amount of synthesized organic acids - lactic, propionic and acetic also had differences. Their highest concentration was observed during the joint fermentation of cultures of microorganisms - lactic acid and propionic acid bacteria.

The results of the studies made it possible to conclude that for the highest fermentation efficiency of alfalfa brown juice, it is preferable to use the combined use of these cultures of microorganisms - lactic acid and propionic acid bacteria.

The ratio of organic and mineral substances in the pressed residue was more balanced for feeding cattle than in the original green mass of alfalfa. As a result of the decrease in protein content, the sugar-protein ratio has become more favorable for ensuring fast fermentation of the feed and the preservation of nutrients in the absolutely dry matter (DSM) of the feed. The chemical composition of green mass, products of its processing and the requirements for the quality of haylage adopted in the Russian Federation are presented in Table 1.

Table 1. Chemical composition of alfalfa leaf mass and products of its processing, $\%$ ACB

\begin{tabular}{|l|l|l|l|l|l|l|}
\hline Product & SV & $\mathrm{pH}$ & Protein & Fat & Cellulose & Ash \\
\hline $\begin{array}{l}\text { Leaf mass of } \\
\text { alfalfa }\end{array}$ & 24.15 & & 21.42 & 455 & 28.53 & 8.38 \\
\hline Pross-sediment & 37.80 & & 16.25 & 4.03 & 37.25 & 9.57 \\
\hline Brown juice & 5.60 & 6.51 & 10.61 & 1.65 & 10.10 & 16.50 \\
\hline Haylage 1/2 cl. & $\begin{array}{l}45-55 \\
/ 45-55\end{array}$ & & $\mathrm{n} / \mathrm{m} 16 / 15$ & & $\mathrm{n} / \mathrm{b} 26 / 27$ & $\begin{array}{l}\mathrm{n} / \mathrm{b} \\
10 / 11\end{array}$ \\
\hline
\end{tabular}


In the control, the original pressed alfalfa residue was hayed without the addition of fermented brown juice.

The introduction of brown juice, enriched with the metabolic products of lactic acid and propionic acid bacteria - organic acids, was carried out to intensify the process of fermentation of the feed. The chemical composition of the control and experimental feed samples is presented in Table 2 .

Table 2. Chemical composition, \% ASB, haylage from the press residue with the introduction of fermented brown juice

\begin{tabular}{|c|c|c|c|c|}
\hline \multirow[b]{3}{*}{ Indicator } & \multicolumn{4}{|c|}{ Nutrient content of haylage } \\
\hline & \multirow{2}{*}{$\begin{array}{l}\text { from the } \\
\text { original } \\
\text { pressed } \\
\text { residue }\end{array}$} & \multicolumn{3}{|c|}{$\begin{array}{l}\text { from the press residue with the introduction of } \\
\text { brown juice, fermented }\end{array}$} \\
\hline & & lactobacilli & $\begin{array}{l}\text { propionic acid } \\
\text { bacteria }\end{array}$ & $\begin{array}{l}\text { a mixture of } \\
\text { lactic acid and } \\
\text { propionic acid } \\
\text { bacteria }\end{array}$ \\
\hline Dry matter & 38.12 & 38.05 & 38.43 & 38.54 \\
\hline Protein & 14.52 & 15.73 & 15.57 & 16.22 \\
\hline Fat & 4.04 & 4.43 & 4.78 & 4.72 \\
\hline Cellulose & 37.73 & 37.88 & 37.75 & 36.92 \\
\hline Ash & 9.01 & 9.44 & 9.47 & 9.55 \\
\hline Total organic acids & 2.43 & 2.51 & 2.49 & 2.58 \\
\hline \multicolumn{5}{|l|}{$\begin{array}{l}\text { Acid content, } \\
\% \text { from the sum: }\end{array}$} \\
\hline lactic & 51.7 & 63.2 & 62.7 & 64.4 \\
\hline acetic & 46.1 & 36.8 & 37.3 & 35.6 \\
\hline oily & 2.2 & 0 & 0 & 0 \\
\hline Feed units & 0.59 & 0.74 & 0.74 & 0.77 \\
\hline
\end{tabular}

The results of the study showed that the introduction of the fermented brown juice of the pressed alfalfa into the biomass activated and intensified the process of fermentation of the feed.

The $\mathrm{pH}$ level in all experimental variants was lower than in the control. The content of organic acids as a percentage of their total also differed from the control sample - the content of lactic acid was greater (51.7\%) in relation to acetic acid (46.1\%), in the control and 62.7$64.4 \%$ and $35.6-37.3 \%$ in experimental samples, respectively.

The presence of butyric acid, indicative of food spoilage, was not detected in the test samples.

Based on the results of the analysis of the chemical composition of the prepared silage from the pressed residue, it was found that the use of fermented brown juice reduced the loss of protein and other nutrients in comparison with haylage prepared from the pressed residue stored without the introduction of brown juice.

In terms of feed value - the content of nutrients, the ratio of organic acids and the content of feed units, haylage prepared from the pressed residue with the introduction of brown juice with the introduction of monocultures of lactic acid and propionic acid bacteria differed insignificantly.

The indicators of the fodder value of haylage with the introduction of brown juice fermented with a mixture of bacterial cultures were higher, on the basis of which it was concluded that it is preferable to use this particular version of brown juice fermentation for haylage.

The prepared haylage in all variants of the experiments met the requirements for haylage 
of the 2nd class adopted in the Russian Federation - it had a fruity smell, a grayish-green color, and retained its natural structure.

The assessment of microbial contamination and potential harmlessness of silage from the pressed alfalfa residue to animals was also carried out. When storing haylage, there is formation and development of mold in its volume, which requires an assessment of its hygienic quality [15].

During the toxicological assessment, the amount and composition of competitive undesirable microflora - bacteria, yeast, microscopic fungi - were determined.

When silaging the press residue with the introduction of enriched brown juice with propionic acid bacteria, which have antagonistic activity to a group of pathogenic bacteria, and lowering the $\mathrm{pH}$ of the medium, conditions were created to reduce the microbiological contamination of feed.

In the initial leafy mass and the pressed alfalfa residue, the total number of microorganisms, including lactic and propionic acid bacteria was $3 \cdot 10^{3}, \mathrm{CFU} / \mathrm{g}$ (number of colony forming units in $1 \mathrm{~g}$ ), which did not exceed the norms established in the Russian Federation for starter bacterial cultures. In the leafy mass, the content of bacteria of the Escherichia coli group was also found, which did not exceed the established requirements.

In the experimental variants of the prepared haylage, the total number of microorganisms, including lactic and propionic acid bacteria, decreased and amounted to $3 \cdot 10^{5} \mathrm{CFU} / \mathrm{g}$.

The death of the accompanying bacterial and fungal flora with a rapid decrease in $\mathrm{pH}$ was explained by the fact that the resulting organic acids had a preservative effect and suppressed the development of undesirable microorganisms.

When studying bacterial contamination, no deviations from the requirements established for haylage were found. The number of lactic acid and other microorganisms corresponded to the required level. bacteria of the genus Erwina and belonging to the group of Escherichia coli. pathogenic bacteria were not sown. Staphylococcus aureus producing enterotoxin was not detected.

Thus, during silage of the pressed alfalfa residue with the addition of fermented brown juice, there was a decrease in the contamination of the feed with bacterial and fungal flora compared to the leafy mass and made it possible to obtain feed that was harmless to animals.

\section{Conclusion}

The introduction into the biomass of the pressed alfalfa residue of brown juice fermented with a mixture of strains of lactic acid and propionic acid bacteria activated and intensified the process of fermentation of the feed.

The $\mathrm{pH}$ level in all experimental variants was lower than in the control. The content of organic acids as a percentage of their total also differed from the control sample - the content of lactic acid was greater than that of acetic acid.

The use of fermented brown juice reduced the loss of protein and other nutrients compared to haylage made from pressed residues stored without the addition of brown juice.

In terms of feed value - the content of nutrients, the ratio of organic acids and the content of feed units, haylage prepared from the pressed residue with the introduction of brown juice with the introduction of monocultures of lactic acid and propionic acid bacteria differed insignificantly.

The indicators of the fodder value of haylage with the introduction of brown juice fermented with a mixture of bacterial cultures were higher, on the basis of which it was concluded that it is preferable to use this particular version of brown juice fermentation for haylage.

The prepared haylage in all variants of the experiments had a fruity smell, grayish-green color, retained its natural structure, in terms of feed and energy value met the regulated 
requirements in the regulatory documents adopted in the Russian Federation for good-quality class 2 haylage.

The obtained results of the studies made it possible to conclude that the developed method for processing the leafy mass of alfalfa, which provides for the utilization of the pressed residue formed as a by-product by silage with the introduction of brown juice fermented with the help of the starter culture of lactic acid and propionic acid bacteria strains, makes it possible to obtain benign haylage, according to organoleptic, indicators of feed, energy value that meets the established requirements, harmless for inclusion in the diets of farm animals.

The preparation of haylage from plant processing waste makes it possible to obtain more nutrients from a unit of the same sown area, to reduce the cost of livestock products in comparison with traditionally produced feed $[16,17]$.

The novelty of the work consists in the developed method of fermentation and conservation of waste products from the processing of green mass of alfalfa to obtain environmentally friendly haylage, which is not inferior in quality to that prepared from traditional raw materials, contributing to the increase in the complexity of the use of plant resources and the protection of the environment.

\section{References}

1. C. E. Müller, M. Johansson, A.C. Salomonsson, A. Albihn, Grass and Forage Science 69(1), 74-89 (2014)

2. C. E. Müller, Grass and Forage Science 73(4), 815-827 (2018) doi.org/10.1111/gfs.12387.

3. C. E. Müller, Forages and grazing in horse nutrition 8, 237-253 (2012)

4. C. E. Müller, Applied Animal Behaviour Science 134(3-4), 144-151 (2011) DOI: 10.1016/j.applanim.2011.08.005

5. I. Zanina, M. Molev, A. Iliev, Y. Chertov, N. Stuzhenko, Metallurgical and Mining Industry 7(10), 25-29 (2015)

6. N. Ovchinnikova. Innovative Technologies in Science and Education (ITSE-2020) 210 (2020) DOI: 10.1051/e3sconf/202021014002.

7. M. Cristina, N. Agarussi, O. G. Pereira, R. A. de Paula, V. P. da Silva, J. P. Santos Roseira, F. F. e Silva, Sci Rep. 9, 8007 (2019) doi:10.1038/s41598-019-44520-9.

8. C. E. Müller, K. Nostell, J. Bröjer, Livestock Science 186, 46-52 (2016) https://doi.org/10.1016/j.livsci.2015.06.011.

9. V. Kireeva, T. Rasskazova, N. Serbulova, Sustainable Development of Mountain Territories 10(38), 493-499 (2018) doi:10.21177/1998-4502-2018-10-4-493-499.

10. J. M. Wilkinson, D. R. Davies, Grass and Forage Science 8(1), 1-19 (2013) https://doi.org/10.1111/j.1365-2494.2012.00891.X

11. F. Li, Z. Ding, A. T. Adesogan, W. Ke, Y. Jiang, J. Bai, S. Mudassar, Y. Zhang, W. Huang, X. Guo, Animals 10(9), 1575 (2020) https://doi.org/10.3390/ani10091575

12. X. S Guo, D.J. Undersander, D. K. Combs, J. Dairy Sci 96(3), 1735-44 (2013) doi: 10.3168/jds.2045-5786. Epub 2013 Jan 16.

13. R. E. Muck, E.M.G. Nadeau, T.A. McAllister, F.E. Contreras-Govea, M.C. Santos, L. Kung Jr, J Dairy Sci. 101(5), 3980-4000 (2018) doi: 10.3168/jds.2017-13839.

14. B. F. Carvalho, G.F.C. Sales, R.F. Schwan, C.L.S. Ávila, J Appl Microbiol 130(2), 341355 (2021) doi: 10.1111/jam.14833 https://doi.org/10.1111/j.1365-2494.2011.00803.X 
15. V. Gaponov, D Kuznecov, V Dudnik, V Kireeva, A Litvinov, IOP Conference Series: Materials Science and Engineering, International Scientific and Practical Conference Environmental Risks and Safety in Mechanical Engineering (ERSME-2020). Rostovon-Don, Russia 1001, 012109 (2020) doi:10.1088/1757-899X/1001/1/012109

16. K. Kobzev, N. Kobzeva, V. Chegge, M. Balinskaya, E. Bozhenko, S. Saakian., D. Sarkisian, International Scientific and Practical Conference on Environmental Risks and Safety in Mechanical Engineering, ERSME 2020, 217, 14, 11001 (2020) DOI:10.1051/e3sconf/202021711001

17. L. Enalyeva, D. Rudoy, Alekseyev, T. Tupolskih, V. Lodyanov, 8th Innovative Technologies in Science and Education, ITSE 2020 210, 4, 03004 (2020) DOI: $10.1051 / \mathrm{e} 3$ sconf $/ 202021003004$ 